\title{
A practice for all seasons: male circumcision and the prevention of HIV transmission
}

\author{
Krishna C. Addanki ${ }^{1}$, D. Gene Pace ${ }^{2}$, Omar Bagasra ${ }^{1}$ \\ ${ }^{1}$ South Carolina Center for Biotechnology, Claflin University, Orangeburg, SC 29115, South Carolina, USA \\ ${ }^{2}$ Department of English and Foreign Languages, Claflin University, Orangeburg, SC 29115, South Carolina, USA
}

\begin{abstract}
HIV/AIDS as a global epidemic has exerted its terrifying influence for quite some time now. Currently, a vaccine for its prevention appears to be near impossible. HIV has spread across the globe without deference to gender, race, religion, or socioeconomic status. Despite a growth in HIV awareness and interventions, there are perplexingly different prevelence rates in different countries with seemingly similar behavioral patterns. In this review we examined these variances in infection rates and found conclusive evidence that male circumcision makes a major difference. Removal of the foreskin of the penis (male circumcision, MC, C) is known to significantly reduce female-to-male HIV transmission through sex, which then decreases male-to-female transmission. Three recent randomized controlled studies from Africa have shown that circumcision offers a $60 \%$ to $70 \%$ protective effect against heterosexual acquisition of HIV. The protective effect of circumcision against HIV, known since the 1980s, has been confirmed by more than 30 studies before these three famous randomized controlled trials, which are the criterion standard of clinical research. The global epidemiology data clearly indicates a reduction of over $99.9 \%$ in HIV prevalence in countries where $\mathrm{C}$ rate is over $80 \%$. As we show in this review, MC not only reduces HIV but also other sexually transmitted diseases (STDs). Circumcision's decisive role in reducing the effect of HIV transmission has been so convincing that it has now been accepted officially by the WHO, UN, and NIH. Moreover, many nations have initiated adult circumcision as a public health measure.
\end{abstract}

Key Words: Circumcision, HIV/AIDS, .Prevention, Vaccine

J Infect Developing Countries 2008; 2(5):328-334.

Received 13 June 2008 - Accepted 26 August 2008

Copyright ( $) 2008$ Addanki et al. This is an open access article distributed under the Creative Commons Attribution License, which permits unrestricted use, distribution, and reproduction in any medium, provided the original work is properly cited.

\section{Introduction}

HIV/AIDS is a global epidemic that has attacked all societies since the virus began its rapid spread in the late twentieth century. The failure of vaccine creation attempts underscores the sad reality that a vaccine for its prevention may still be decades away. To spread awareness of how the virus is transmitted is a primary preventative intervention that is essential to slow the rates of infection and reduce the incidence rate. Dedicated work from several researchers has helped to develop preventive techniques, which can quell the infection and perhaps answer the yet unanswered question: Why is there so much variation in the prevelence of HIV-1 in different parts of the world, and even in nations that share geographic borders? The twentieth century saw the rise of penile cancer in the 1930s [1], followed by a rise in cervical cancer in the fifties, an increase in sexually transmitted diseases (STDs) in the sixties, more frequent urinary tract infections in the 1980s [2] and, most alarming of all, AIDS in the 1990s. Troubling diseases associated with the reproductive system have attacked the health of large populations worldwide.

HIV has proliferated across the globe, undeterred by social status or geography, tormenting humanity without regard to race, gender, or background. It has forged alliances, albeit unwittingly, with individuals who share needles, engage in unprotected sex, and transmit the virus to newborns who are infected in utero or during childbirth. It rarely stems from transfusions of contaminated blood from HIV-infected persons. Although the means of transmission have been well established, it has been puzzling why viral prevelence is so markedly uneven in different parts of the world, or why it causes significant variance in infection rates among different religious groups within the same region.

However, the case of homeless Muslim and Hindu men in Kolkata, India, offers significant insight, since the circumcised Muslims have experienced far less infection than the uncircumcised Hindus, suggesting that failure to carry out this simple procedure, for 
religious or other reasons, may be a life-or-death choice $[3,4]$. Armed with this simple and inexpensive procedure, the world has a potent weapon with which to assail a cruel viral enemy that has eluded the frail assaults by the creators of failed vaccines. In the defensive contest against deadly diseases that form under the foreskin [5], the best remedy is simply to eliminate their breeding ground, to "amputate" their foreskin fortress. In the case of STDs, variation in social norms and mores (including MC) provides greater explanatory power for the variation in disease prevelence than do geography and social class [6].

The goal of this article is to analyze the impact of circumcision on the reduction of HIV infection rates from infected females to males, and to establish a correlation between global HIV transmission and circumcision rates in various geographical areas.

We maintain that there is a strong and consistent association between a higher level of male circumcision (MC) and a lower rate of HIV (and other STD) infection. Such a connection suggests that MC is not merely a personal want but a public need if AIDS is to be curtailed.

\section{Significance of the Study}

The establishment of a significant connection between circumcision and HIV transmission is of immense importance in terms of human life, and the quality thereof, since MC would reduce HIV prevelence across the globe.

We maintain that through proper educational programs and online information sources, the acceptability of MC by high-risk populations could be improved, and that such a behavior shift would dramatically reduce the overall incidence of HIV.

This study provides the necessary data to assist researchers, advocates, health professionals, counselors, educators, and policymakers to develop appropriate interventions aimed at increasing $\mathrm{MC}$ worldwide.

\section{MC and Hygiene}

Male circumcision, the surgical removal of some of the foreskin of the male penis, is an ancient practice, as evidenced by cave drawings on ancient Egyptian tombs [7-9] as well as by references to the practice in written historical sources. MC has been called the oldest, most controversial operation in the history of the world [10], and is practiced for religious, social, cultural, and medical reasons. In the West, MC has been practices for many reasons, including personal hygiene, cosmetic appearance, tribal identity, and religious observance.
Controversy over MC has been fueled by debates over such issues as whether the practice increases or decreases fertility, benefits or harms health, contributes to piety or worldliness, and helps or hinders sexual activity $[7,11]$.

Far more than a religious practice, MC wisely cries out for universal implementation. It has far-reaching medical and social consequences, relating not only to personal and group identity, but also to personal health and global epidemiology. It relates to the incidence of HPV, HIV, and a number of other viral and bacterial pathogens, for the foreskin promotes the initial survival and eventual transmission of these and many other microorganisms [12,13]. The authors of the Orange Farm study (named after a location near Johannesburg, South Africa) state that "Langerhans immune cells found under the foreskin are observed to be the prime targets of HIV" [14]. The moist nature of the area between glans and foreskin invites viral replication [15], and tiny abrasions in the delicate skin of the inner surface of the foreskin during intercourse can provide a portal of entry for HIV, thereby putting uncircumcised men at a much higher risk of infections than if they had been circumcised [16,17]. The association between the foreskin and the acquisition of HIV from a sexual partner (and the subsequent development of AIDS) has been investigated through data analysis and clinical trials in the African population [18]. The majority of African nations exhibit high rates of HIV infection that is primarily transmitted through the unsafe sexual practices of heterosexual pairs.

\section{Clinical Trials}

MC practices vary throughout Africa [19], and HIV rates vary accordingly. Countries in West Africa, where male circumcision is common, have HIV prevelence levels well below those of countries in eastern and southern Africa with low circumcision rates [16,20]. Data from cross-sectional observational studies conducted since the mid-1980s have shown that circumcised men have a lower prevelence of HIV infection than uncircumcised men [21]. The authors of the Orange Farm study [15] conclude: "Male circumcision provides a degree of protection against acquiring HIV infection equivalent to what a vaccine of high efficacy would have achieved."

Multiple cross-sectional, prospective, and ecologic (population-level) studies have identified a lack of male circumcision as a risk factor for HIV infection [22,23]. One published article, which focuses on the systematic review and meta-analysis of heterosexual transmission 
of HIV in Africa [24], summarizes 19 cross-sectional studies, five case control studies, three cohort studies, and one partner study, and then concludes that MC exerts a substantial protective effect vis-à-vis risk of HIV infection. The relative risk for HIV infection was observed to be $44 \%$ lower in circumcised men after adjusting the confounding factors in population-based studies [25], and an even stronger association, 71\% adjusted relative risk, for high-risk men (i.e., patients at STD clinics). Another peer-reviewed article, which assesses 10 potential factors and was stratified by study population [26], found that 16 of 35 observational investigations that involved the general population showed inconsistent results. One large cohort study in this group of 16 showed a significant protective effect, with odds of infection being $42 \%$ lower in circumcised men [27]. The remaining 19 studies involving high-risk populations showed consistent protective effect [28]. In an important trial in Kisumu, Kenya, involving 2,784 HIV-negative men [29], there was a 53\% reduction of HIV acquisition in circumcised men relative to uncircumcised men, while a trial of 4,996 HIV-negative men in Rakai, Uganda showed that HIV acquisition was reduced by $48 \%$ in circumcised men [30]. Three randomized, controlled clinical trials were undertaken in Africa to determine whether circumcision of adult males helps reduce their risk for HIV infection. The study conducted in South Africa [15] was so conclusive that it was stopped in 2005; the Kenya [29] and Uganda [30] studies were both stopped in 2006 after their interim analyses clearly revealed that medical circumcision reduced risk of HIV infection.

In these studies, men who had been randomly assigned to the circumcision group had a 60\% (South Africa), $53 \%$ (Kenya), and $51 \%$ (Uganda) lower incidence of HIV infection compared to men assigned to the wait list group to be circumcised at the end of the study. In all three studies, a few men who had been assigned to the circumcised group did not undergo the procedure after all, and vice versa. When the data were reanalyzed to account for these deviations, men who had been circumcised had a 76\% (South Africa), 60\% (Kenya), and 55\% (Uganda) reduction in risk of HIV infection compared to those who were not circumcised, persuasive evidence of the protective effect of circumcision.

\section{MC and HIV: A Geographical Approach}

We next turn to an examination of nations with very high and very low HIV prevelence, to look for potential correlations between MC and HIV rates.
India: One of the geographically largest and most populous countries on earth, India has $0.9 \%$ of its population is living with HIV/AIDS, and is one of the leading nations in total number of persons living with HIV [31]. With a population of over one billion inhabitants, only a meager $15 \%$ (mostly Muslims) of its population is believed to be circumcised [32]. The rate of HIV infection in recent years has increased exponentially as a result of unsafe sexual practices with multiple sexual partners [33] and the population giant's dismal MC record. The estimates of HIV prevelence are expected to peak at $1.9 \%$ by the year 2019 [34], a figure that bodes ill not only for India but for the entire world. The inverse relationship between HIV prevelence and circumcision rates helps to explain the bleak situation into which India continues to slide.

Botswana: A landlocked nation in Southern Africa, this nation has the dubious distinction of ranking second highest in HIV prevelence on the continent, with an appalling $24.1 \%$ of its population carrying HIV [31]. This nation of 1.8 million inhabitants has fewer than $15 \%$ of its males circumcised, and about $70 \%$ of its 15 to 49-year-olds have HIV/AIDS. High HIV prevelence among a population with very low circumcised group accounts for the lack of protection against HIV infection [35]. The study involving a cross-sectional survey in Botswana concluded that $89 \%$ of the population supported the need for circumcision [36]. This MC acceptability ratio among the public indicates a realization of the link between circumcision and HIV transmission [37].

Algeria: The second most spacious country on the African continent, with 33.5 million people, Algeria stands unique from the rest of Africa with less than $0.1 \%$ of the population carrying HIV/AIDS [31]. With over $80 \%$ of its men circumcised, in part the result of an MC trend that extends centuries into the past, Algeria's statistics contrast starkly with Botswana's bleak figures. The high circumcision rate in Algeria, compared the low rate in Botswana, shows a significant inverse correlation in the HIV prevelence rates for these two African nations.

Australia: A nation with great ecological diversity, and surrounded by oceans, Australia has varying HIV prevelence rates. Although about $90 \%$ of its male population was circumcised in the early 1970s, that enviable figure has declined by about $20 \%$ [26]. Australia is a nation ideally suited for observation of the interactive relationship between HIV infection and MC prevelence. By 2006 , less than $0.1 \%$ of 15 - to 49 -yearolds were living with HIV/AIDS [31]. This study group 
deals significantly with individuals born during the time of high circumcision rates (1960-1980), which suggests why HIV rates have remained low in Australia. Given the current decline in circumcision rates, one would expect to see a rise in HIV/AIDS cases in the coming decades.

USA: A multicultural nation with great geographic diversity, the United States of America ranks $15^{\text {th }}$ (World Health Organization) for its health care systems. Obesity, the prosperous nation's major public health problem, could one day be surpassed by STDs, given the declining MC percentage and deteriorating sexual behavior [38]. Statistical data from the 2003 Nationwide Hospital Discharge Survey show that circumcision rates fell from $64.7 \%$ in 1980 to $59.0 \%$ in 1990 , then rose to $64.1 \%$ in 1995 , and fell again to only $55.9 \%$ in 2003 [39]. Despite a troubling decline in the MC rate in recent decades, the US has never fallen out of the optimal range of 55\%-65\% MC rate. The nation's moderate HIV infection rate ( one million HIV infected people) coincides with the inverse proportionality of $\mathrm{MC}$ and HIV rates observed elsewhere.

Mauritania: Mauritania, also known as the Islamic Republic of Mauritania, is surrounded by water, by land, and by nations with high HIV rates (Mali and Senegal) and low rates (Algeria and Morocco). This nation falls into a moderate HIV infection category, with $0.7 \%$ of its population infected [31] with HIV/AIDS. A historically Islamic nation that was subject to French colonialism until independence, Mauritania has a blend of ethnic groups that practice male circumcision for religious and cultural reasons. Mauritania is unusual as a Western Africa nation because of its inclusion in the moderate HIV infection group. Male circumcision seems to be the major contributing factor for its controlled HIV prevelence; nearly $60 \%$ of its males have been circumcised [40].

In our analysis, we grouped nations according to their level of HIV prevelence by drawing upon a recently published article titled "2006 World population DATA SHEET" from the Population Reference Bureau (PRB) for statistical data. We focused on the high-risk group between ages 15 and 49 in order to compare rates of infection. Figure 1 provides a visual representation of our findings about HIV infection throughout the world. Nations were categorized as high incidence $(\geq 0.9 \%$, red); moderate ( $\geq 0.1 \%-0.9 \%$, pink); and low $(\leq 0.1 \%$, green) in terms of their HIV prevelence for the at-risk group. In order to roughly estimate national MC rates, we relied upon a map (Figure 2) generated by UNAIDS for a 5 December 2006 presentation in Geneva,
Switzerland, titled "Overview of the current evidence on male circumcision and HIV prevention."

Figure 1. Global HIV Prevalence.

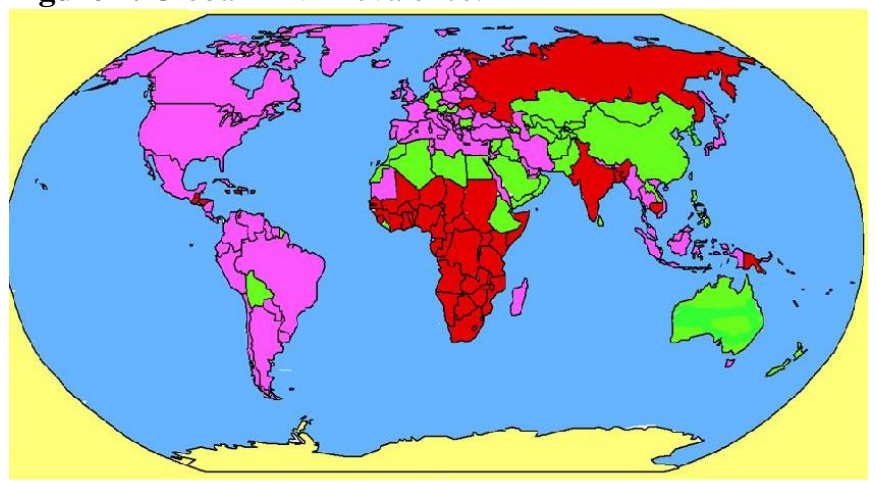

Our analysis demonstrated that there was a significant correlation between $\mathrm{MC}$ rates and HIV infection rates. Countries with low MC rates $(<20 \%)$ tended to have high $(\geq 0.9 \%)$ HIV prevelence in the 15 to 49 age group. Conversely, nations with high $\mathrm{MC}$ rates $(>80 \%)$ experienced low $(<0.1 \%)$ HIV infection rates for the same high-risk group. The trend continued in Africa and Asia. These data were grouped and presented using graphs to display the correlation. Figures 3 and 4 show that in areas where circumcision is an age-old practice (such as Algeria and Niger), HIV prevelence is low, whereas in countries where only a small minority of the population practices MC (such as India and Swaziland), HIV incidence is high, suggesting a significant correlation between MC and HIV. Therefore, our grouping of the nations based on HIV infection rates shows promising data when compared to the percent of people circumcised in each of the nations.

Figure 2. Prevalence of Male Circumcision, UNADIS, Geneva, Switzerland, 2005.

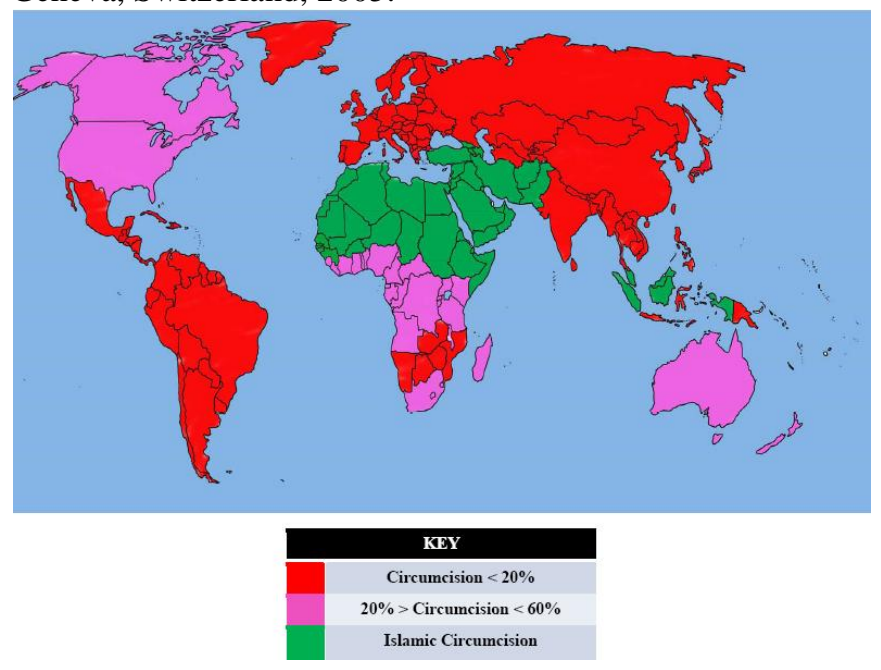


The statistical information for Figures 3 and 4 was gathered from the world population data sheet published by the Population Reference Bureau in 2006. The parameters are set to choose nations that fall into the criterion of low male circumcision $(<20 \%$ of the population) and high male circumcision $(>80 \%)$. The HIV prevelence of individual nations was observed and matched with the circumcision prevelence. Strength in this study has been measured using data from appropriate statistical tests. To determine that the MCHIV association is consistent, we drew on results that are replicated in other studies that use different testing methods. We analyzed data from three randomized, controlled clinical trials conducted in Africa to determine whether adult MC helps reduce these men's risk for HIV infection. The study conducted in South Africa was stopped in 2005 and those in Kenya and Uganda were stopped the following year after their interim analyses persuasively indicated that medical circumcision reduced male participants' risk of HIV infection. In these studies, men who had been randomly assigned to the circumcision group had a 61\% (South Africa), 53\% (Kenya), and 48\% (Uganda) lower incidence of HIV infection compared to men assigned to the wait list group to be circumcised at the end of the study.

Figure 3. Correlation of HIV and Male Circumcision Prevalence in Africa.

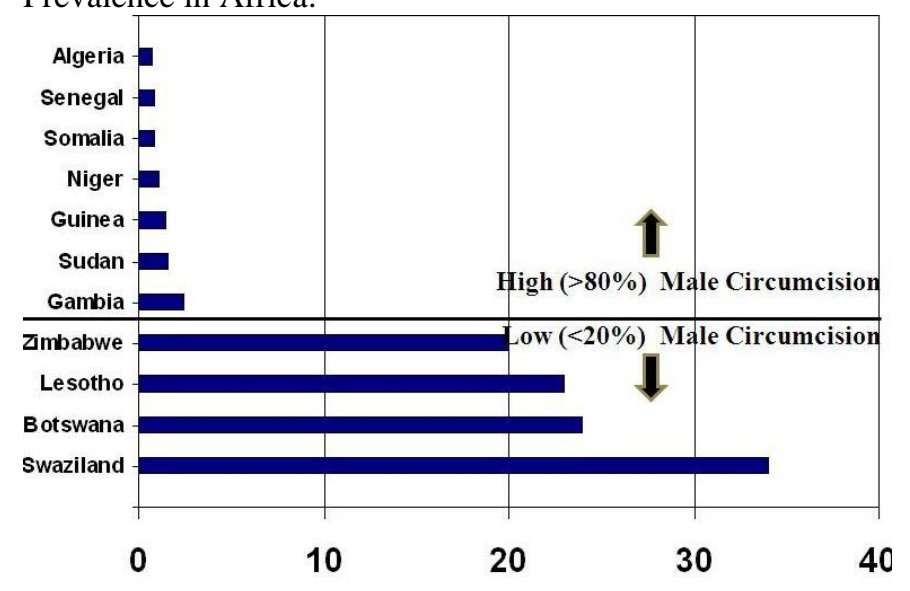

According to Robert Bailey, professor of epidemiology and anthropology at the University of Chicago, "There are now 40 studies that have shown that men who are not circumcised are at anywhere from a 1.8 to an 8.2-fold increased risk for HIV infection" (cited by Collymore). Results from the previously mentioned studies show a consistent occurrence of $50 \%$
HIV reduction on average in circumcised populations as compared to uncircumcised populations.

The MC-HIV association agrees with the currently accepted understanding of pathological processes. For instance, "The foreskin has HIV target cells which make it easy for HIV transmission and acquisition," said Godfrey Kigozi, a researcher associated with Uganda's Rakai Health Sciences Program (cited by Fink). Jimmy Volmink, director of the South African Medical Research Council's Cochrane Centre, explained, "Langerhans immune cells found under the foreskin are prime targets of HIV. The virus is capable of surviving longer in the moist environment between the glans and foreskin. Lesions from sexually transmitted disease occur under the foreskin thereby increasing the HIV infection" (cited by Beukes). The impact of the foreskin on accelerating HIV infection rates is further explained by the small tears in the delicate skin of the inner surface of the foreskin during intercourse, especially if the affected area is made more delicate by moistness caused by the foreskin. As the foreskin retracts during intercourse, HIV vulnerability increases substantially, as does the likelihood of contracting genital ulcer disease (GUD), which greatly facilitates HIV invasion and infection.

Figure 4. Correlation of HIV and Male Circumcision Prevalence in Asia.

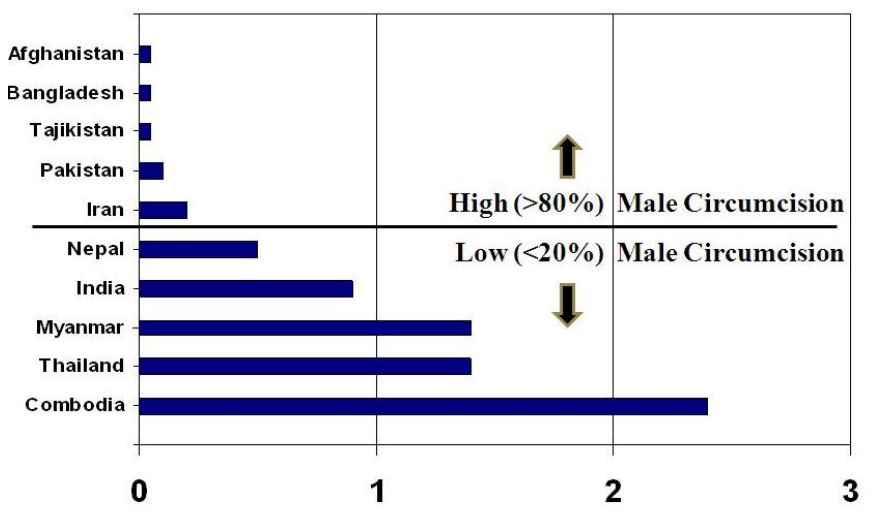

New methods of HIV control have been proposed by the World Health Organization, the Bill and Melinda Gates Foundation, and by many other health care foundations and agencies. These methods include, but are not limited to the following: (i) a natural microbicide, such as intravaginal lime or lemon juice that could kill HIV in the vagina upon application; (ii) intravaginal estrogen that is known to keratinize the vagina with a topical application, and which could thicken the vagina to protect against HIV infection, 
while providing contraceptive efficacy without the need of an oral contraceptive pill; (iii) post-coital penile hygiene, which involves wiping the penis immediately after intercourse with lime juice, lemon juice, or vinegar to kill the HIV virus before it can infect; (iv) Photo Voice, which involves asking schoolchildren in developing countries to photograph their impressions of HIV/AIDS as a means of encouraging them to discuss the subject openly, and to develop their own preventative strategies; (v) male circumcision, which removes the main site of HIV entry, and results in a seven- to nine-fold reduction in susceptibility to infection. This final approach is attracting the attention of a large number of HIV health care providers, for its significant potential to reduce HIV transmission, and to control HIV/AIDS.

\section{Discussion}

The risk of contracting HIV through sex is a very important parameter to consider in any analysis of the spread of HIV. Substantially reduced risk helps to substantially reduce incidence of the epidemic. MC, as this article and others have demonstrated, has a significant impact on HIV transmission reduction, and its protective capacity also holds promise for other sexually transmitted diseases. Helen Weiss, in her insightful article, proposes a statistical model that assesses the lowered risk of circumcised men in terms of STDs. Among the benefits of neonatal circumcision is its impressive protective effect against urinary tract infections in infants. One multi-site cross-sectional analysis found that MC has a marked effect $(63 \%$ reduction rate) on the prevention of most Human Papilloma Virus (HPV) strains. Urinary tract infections in circumcised boys are far less frequent (one to 12) than for uncircumcised boys. Uncircumcised men have an increased risk of contracting syphilis by a factor of between 1.5 and 3.0. They are two and one-half times as likely to suffer from cancroids, twenty-two times as likely to have penile cancer, and their partners are between 2.0 and 5.8 times as likely to suffer from cervical cancer. As Maria Wawer reminds us, circumcision is a protective procedure that is only done once, and then provides lifetime protection.

To date, the most reliable data about the MC-HIV relationship come from three major studies conducted in Africa. To further correlate the impact of male circumcision on HIV transmission, more studies need to be done focusing on populations outside of Africa, especially in countries such as India and the nations of Latin America, where levels of circumcision are low.
Additional studies of male-to-male transmission would likely strengthen the thesis of previous studies mentioned in this article.

As is generally the case, benefits are accompanied with disadvantages, including unintended consequences that economists, political scientists, and others call externalities. It is important to understand that while MC protects against HIV transmission from female to male, it is not a panacea, nor is it an excuse for moral irresponsibility, or lack of appropriate precautions in intimate relations.

\section{Conclusion}

AIDS can now be delayed but not stopped. Imperfect human behavior, lack of a vaccine, and many social and cultural factors combine to threaten an increasing number of AIDS victims worldwide. A complete therapy remains elusive, but we still have promising techniques and methodologies that can eventually reduce HIV prevelence. Known methods of preventing or reducing HIV - such as education and behavioral changes, female and male condom usage, and male circumcision-have led to a reduction, by half, in infection rates. Consideration of combination therapy, including all the available means of curtailing HIV, can further enhance the control of HIV transmission. We maintain that it is not enough for persons across the planet to understand that HIV is the virus that causes AIDS; they must also acknowledge that MC is the practice that helps to prevent HIV.

\section{Acknowledgements}

This work was partially supported from the grants from: P2RR16461 (EXPORT): NIH, INBRE and EPS-044760: NSF EPSCoR.

\section{References}

1. Fleiss PM, Hodges F. (1996) Neonatal circumcision does not protect against cancer. BMJ. 312:779.

2. Wiswell TE, Smith FR, Bass JW (1998) Decreased incidence of urinary tract infections in circumcised man. Pediatrics. 74:364-367.

3. Moses S, Bailey RC, Ronald AR (1998) Male circumcision. Assessment of health benefits and risk. Sex Transm Infect 74:368-373.

4. Talukdar A, Khandokar MR, Bandopadhyay SK, Detels R(2007) AIDS. 18;21(16):2231-5

5. Hussain LA, Lehner $T$ (1995) Comparative investigation of Langerhans' cells and potential receptors for HIV in oral, genitourinary and rectal epithelia. Immunology 85:475-484.

6. Serwadda D, Wawer MJ, Musgrave SD, Sewankambo NK, Kaplan JE, Gray RH (1992) HIV risk factors in three geographic strata of rural Rakai District, Uganda. AIDS 6:983989. 
7. Gollaher DL (2000) Circumcision: a history of the world's most controversial surgery. New York, NY: Basic Books, p5372. ISBN 978-0-465-04397-2 LCCN 99-40015.

8. Hodges FM (2001) The ideal prepuce in ancient Greece and Rome: male genital aesthetics and their relation to lipodermos, circumcision, foreskin restoration, and the kynodesme. The Bulletin of the History of Medicine 75 (3): 375-405. PMID 11568485.

9. Wrana, P (1939) Historical review: Circumcision. Archives of Pediatrics 56: 385-392; as quoted in Zoske J (Winter 1998) Male Circumcision: A Gender Perspective. The Journal of Men's Studies 6 (2): 189-208. Retrieved on 2006-06-14.

10. Alanis MC, Lucidi RS (2004) Neonatal Circumcision: A Review of the World's Oldest and Most Controversial Operation. Obstetrical \& Gynecological Survey. 59(5):379395.

11. Quigley M, Munguti K, Grosskurth H, Todd J, Mosha F, Senkoro K, et al. (1997) Sexual behavior patterns and other risk factors for HIV infection in rural Tanzania: a case-control study. AIDS 11:237-248.

12. Donoval BA, Landay AL, Moses S, Agot K, Ndinya-Achola JO, Nyagaya EA, et al. (2006) HIV-1 target cells in foreskins of African men with varying histories of sexually transmitted infections. Am J Clin Pathol 125: 386-91.

13. Moses S, Plummer FA, Bradley JE, Ndinya Achola JO, Nagelkerke NJ, Ronald AR (1994) The association between lack of male circumcision and risk for HIV infection: a review of the epidemiological data. Sex Transm Dis 21:201-210.

14. Soto-Ramirez LE, Renjifo B, McLane MF, Marlink R, O'Hara C, Sutthent R, et al. (1996) HIV-1 Langerhans' cell tropism associated with heterosexual transmission of HIV. Science 271:1291-1293.

15. Auvert B, Taljaard D, Lagarde E, Sobngwi-Tambekou J, Sitta R, Puren A, et al. (2005) Randomized, controlled intervention trial of male circumcision for reduction of HIV infection risk: The ANRS 1265 trial. PLoS Med. Nov;2(11):e298. Epub 2005 Oct 25. Erratum in: PLoS Med. 2006 May;3(5):e298.

16. McCoombe SG, Short RV (2006) Potential HIV-1 target cells in the human penis. AIDS 20

17. Moses S, Bradley J, Nagelkerke N, Ronald AR, Ndinya-Achola JP, Plummer FA (1990) Geographical patterns of male circumcision practices in Africa: association with HIV prevalence. Int J Epidem 19:693-697.

18. Bongaarts J, Reining P, Way P, Conant F (1989) The relationship between male circumcision and HIV infection in African populations. AIDS 3:373-377.

19. Drain P, Halperin D, Hughes J, Klausner J, Bailey R. (2006) Male circumcision, religion, and infectious diseases: an ecologic analysis of 118 developing countries. BMC Infect Dis 6: 172.

20. Anon. (2006) Circumcision: current practice and acceptability. Bull World Health Organ Jul; 84(7):510.

21. Van Howe RS (1999) Circumcision and HIV infection. review of the literature and meta-analysis. Int J STD AIDS 10:8-16.

22. Barongo LR, Borgdorff MW, Mosha FF, Nicoll A, Grosskurth H, Senkoro KP, et al. (1992) The epidemiology of HIV-1 infection in urban areas, roadside settlements and rural villages in Mwanza Region, Tanzania. AIDS 6:1521-1528.

23. Barongo LR, Borgdorff MW, Newell JN, Senkoro KP, Klokke AH, Changalucha J, et al. (1994) Intake of a cohort study of urban factory workers in northwest Tanzania. Risk factors for HIV-1 infection. Trop Geogr Med 46:157-162.
24. Kahn JG, Marseille E, Auvert B (2006) Cost-effectiveness of male circumcision for HIV prevention in a South African setting. PLoS Med 3: e517.

25. O'Farrell N, Egger M (2000) Circumcision in men and the prevention of HIV infection: a 'meta-analysis' revisited. Int $\mathbf{J}$ STD AIDS 11:137-142.

26. Gairdner D (1949) The fate of the foreskin, a study of circumcision. BMJ 2:1433-37.

27. Siegfried N, Muller M, Volmink J, Deeks J, Egger M, Low N, et al. (2003) Male circumcision for prevention of heterosexual acquisition of HIV in men. Cochrane Database Syst Rev. (3):CD003362.

28. Nasio JM, Nagelkerke NJ, Mwatha A, Moses S, Ndinya Achola JO, Plummer FA (1996) Genital ulcer disease among STD clinic attenders in Nairobi: association with HIV-1 and circumcision status. Int J STD AIDS 7:410-414.

29. Bailey RC, Moses S, Parker CB, Agot K, Maclean I, Krieger JN, et al. (2007) Male circumcision for HIV prevention in young men in Kisumu, Kenya: a randomized controlled trial. Lancet 369:643-656.

30. Gray RH, Kigozi G, Serwadda D, Makumbi F, Watya S, Nalugoda F, et al. (2007) Male circumcision for HIV prevention in men in Rakai, Uganda: a randomized trial. Lancet 369:657-666.

31. UNAIDS (2006) World Population Data Sheet.

32. Census of India (2001), Data on religion. Retrieved on November 18, 2006.

33. Aral SO, Holmes KK (1999) Social and behavioral determinants of the epidemiology of STDs: industrialized and developing countries. In: Sexually transmitted diseases. Holmes KK, Mardh PA, Sparling PF, et al. (editors) McGrawHill.

34. International Herald Tribune (2006) The next wave of HIV/AIDS: Nigeria, Ethiopia, Russia, India and China, September, p.3.

35. Carael $\mathrm{M}$, Van de Perre $\mathrm{PH}$, Lepage $\mathrm{PH}$, Allen $\mathrm{S}$, Nsengumuremyi F, Van Goethem C, et al. (1988) Human immunodeficiency virus transmission among heterosexual couples in Central Africa. AIDS 2:201-205.

36. Kebaabetswe P, Lockman S, Mogwe S, Mandevu R, Thior I, Essex M. et.al. (2003) Male circumcision: an acceptable strategy for HIV prevention in Botswana, Sex Transm Infect 79:214-219.

37. Williams BG, Lloyd-Smith JO, Gouws E, Hankins C, Getz WM, Hargrove J, et al. (2006) The potential impact of male circumcision on HIV in sub-Saharan Africa. PLoS Med 3: e262.

38. Anon (1999) Circumcision policy statement. American Academy of Pediatrics. Task Force on Circumcision. Pediatrics 103: 686-93.

39. Kozak LJ, Lees KA, DeFrances CJ (2006) National Hospital Discharge Survey: 2003 annual summary with detailed diagnosis and procedure data. (PDF). Vital Health Statistics 13 (160). Retrieved on 2007-01-30.

40. Fleming ST, Wasserheit JN (1999) From epidemiological synergy to public health policy and practice: the contribution of other sexually transmitted diseases to sexual transmission of HIV infection. Sex Transm Infect 75:13-17.

Corresponding Author: Omar Bagasra, Department of Biology, Director, South Carolina Center for Biotechnology, Claflin University, 400 Magnolia Street, Orangeburg, SC 
29115. Office: (803)535-5253, Fax \#: (803)535-5776, Email: obagasra@claflin.edu

Conflict of interest: No conflict of interest is declared. 